\title{
Revealing Hidden Facts of Li Anode in Cycled Lithium Oxygen Batteries through X-ray and Neutron Tomography
}

Fu Sun, ${ }^{1 * \bowtie}$ Rui Gao, ${ }^{* 2}$ Dong Zhou, ${ }^{3 * 凶}$ Markus Osenberg, ${ }^{1,4}$, Kang Dong, ${ }^{1,4}$ Nikolay Kardjilov, ${ }^{4}$ André Hilger, ${ }^{1,4}$ Henning Markötter, ${ }^{1,4}$ Peter Maria Bieker, ${ }^{3}$ Xiangfeng Liu ${ }^{2 \bowtie}$ and Ingo Manke ${ }^{1}$

\author{
${ }^{1}$ Institute of Applied Materials \\ Helmholtz Centre Berlin for Materials and Energy \\ Hahn-Meitner-Platz 1, 14109 Berlin, Germany \\ ${ }^{2}$ College of Materials Science and Optoelectronic Technology \\ University of Chinese Academy of Sciences, Beijing 100049, P. R. China \\ ${ }^{3}$ MEET Battery Research Center \\ Corrensstraße 46, 48149 Münster, Germany \\ ${ }^{4}$ Institute of Material Science and Technologies \\ Technical University Berlin \\ Strasse des 17. Juni 135, 10623 Berlin, Germany
}

\begin{abstract}
The gap between its successful application and perspective promise of lithium-oxygen battery (LOB) technology should be filled by an in-depth and comprehensive understanding of its underlying working/degradation mechanisms. Herein, the correlation between the morphological evolution of $\mathrm{Li}$ anode and the overall-cell electrochemical performance of cycled LOBs has been revealed for the first time by complementary X-ray and neutron tomography, together with further post-mortem SEM, XRD and FTIR characterizations. It has been disclosed with solid evidence that the irreversible transformation of anode $\mathrm{Li}$ associated with chemical/electrochemical sidereactions does link intimately to the observed electrochemical performance decay. The current discoveries have not only fundamentally enriched our knowledge on the underlying degradation/failure mechanisms of LOBs but also directions for future promising research activities aimed to further enhance their performance can be drawn therefrom.
\end{abstract}




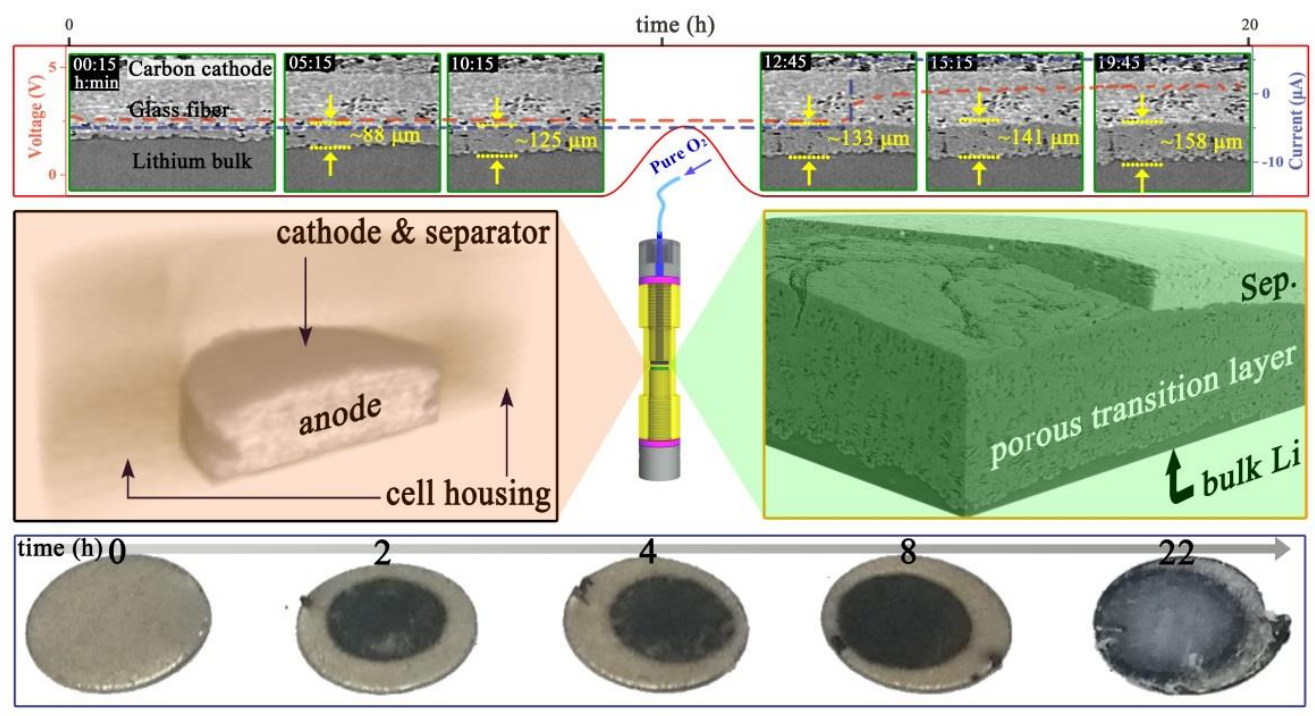

TOC figure

\section{Introduction}

Rechargeable non-aqueous lithium oxygen battery (LOB) is considered as one of the most promising next-generation electrochemical power sources due to its high capacity energy which is comparable with that of gasoline. ${ }^{1-2}$ However, fundamental challenges such as the sluggish kinetics of cathode, chemical instability of electrolyte/Li and very low Coulombic efficiency (CE) during cycling have severely prevented its commercial application. ${ }^{3-5}$ To translate the LOB technology from lab research to market application, multiple strategies such as cathode engineering, ${ }^{6-8}$ solvent additives, ${ }^{9-15}$ reaction redox mediator, ${ }^{16}$ separator modification ${ }^{17}$ and new cell design ${ }^{18}$ have been proposed to overcome its intrinsic challenges. At the same time, various diagnostic tools such as Raman spectroscopy, ${ }^{19} \mathrm{UV}$-vis spectrometry, ${ }^{20} \mathrm{X}$-ray diffraction (XRD), ${ }^{21}$ scanning electron microscopy (SEM), ${ }^{22}$ transmission electron microscopy ${ }^{23}$ and transmission X-ray microscopy, ${ }^{24}$ have been employed to improve our mechanistic understanding towards the mechanisms that determine the overall electrochemical performance. These broad investigations have provided indepth insights into the working mechanism of LOBs and their overall electrochemical performance has been improved significantly since the early studies ${ }^{25}$ Nevertheless, major breakthroughs ${ }^{26}$ that allow LOBs possessing sufficient long-term cycle ability, i.e., competitive to the state-of-the-art lithium ion batteries (LIBs), are still missing. ${ }^{27}$ Recently, neutron and X-ray tomography ${ }^{28-29}$ has been employed to investigate the underlying working/degradation mechanisms of LOBs after cycling, providing direct visual access to the inside morphological/topological changes of the evolved battery components. Unfortunately, a combinatorial in-situlex-situ usage of neutron and X-ray tomography to comprehensively study the general correlation between the internal battery component evolution and external electrochemical behavior has, to the best of the authors' knowledge, not been reported yet. 
Herein, primary research attention has been concentrated on the Li anode side and its correlation to the overall electrochemical performance decay has been systematically investigated by in-situ/ex-situ neutron and X-ray tomography, together with further post-mortem characterization methods. Specifically, three major works have been conducted: 1) In situ monitoring morphological evolution of $\mathrm{Li}$ anode through X-ray tomography during the first cycle; 2) Ex situ charactering the evolved Li metal anode in differently cycled LOBs by X-ray and neutron tomography; 3) Further post-mortem analysis of the cycled $\mathrm{Li}$ anode under electrochemical/chemical conditions through SEM, XRD and FTIR (Fourier-transform infrared spectroscopy) analysis. These extensive and complementary investigations collectively suggest that the irreversible transformation of anode $\mathrm{Li}$ from the original bulk $\mathrm{Li}$ to a porous structure, which is closely associated with the irreversible side-reactions occurring chemically/electrochemically inside LOBs, plays a governing role in the failure/degradation mechanisms of LOB performance. The current discoveries have profoundly improved our mechanistic understanding towards the underlying failure/degradation mechanisms of LOBs and would shed new lights on the future research directions that may bring forth fundamental breakthroughs for their practical commercialization.

\section{Results and Discussion}

Two types of LOBs have been employed in the current research, the customized tomography cell (tomo-cell) and the commercialized Swagelok cell (swag-cell). The photography and the illustration of the customized tomo-cell are shown in Fig. 1, the design of which is a result of an improved version of the previously reported cell ${ }^{30-32}$ with an extra drilling hole in one electrode for oxygen flow. Internal views of this cell can be found in bright blue rectangle in Fig. 1a (measured by neutron tomography) and Fig. 3A1 (measured by X-ray tomography). LOBs assembled with tomo-cells were characterized by X-ray and neutron tomography without cell disassembly. The commercialized Swagelok cells were employed to assemble LOBs for post-mortem characterizations. All LOBs investigated here employed cathode of carbon fiber coated with $80 \%$ rGO catalyst and 20\% PVDF binder, Whatman glass fiber GF/D separator, Li foil anode and ether-based electrolyte. Note that the idea of the combinatorial use of X-ray and neutron tomography is that complementary and comprehensive information can be obtained (for the different imaging techniques, readers can refer to ${ }^{33}$ ). The detailed procedures of cell assembly and electrochemical cycling, tomography measurement and data analysis, along with the postmortem characterizations are presented in the Methods section. 


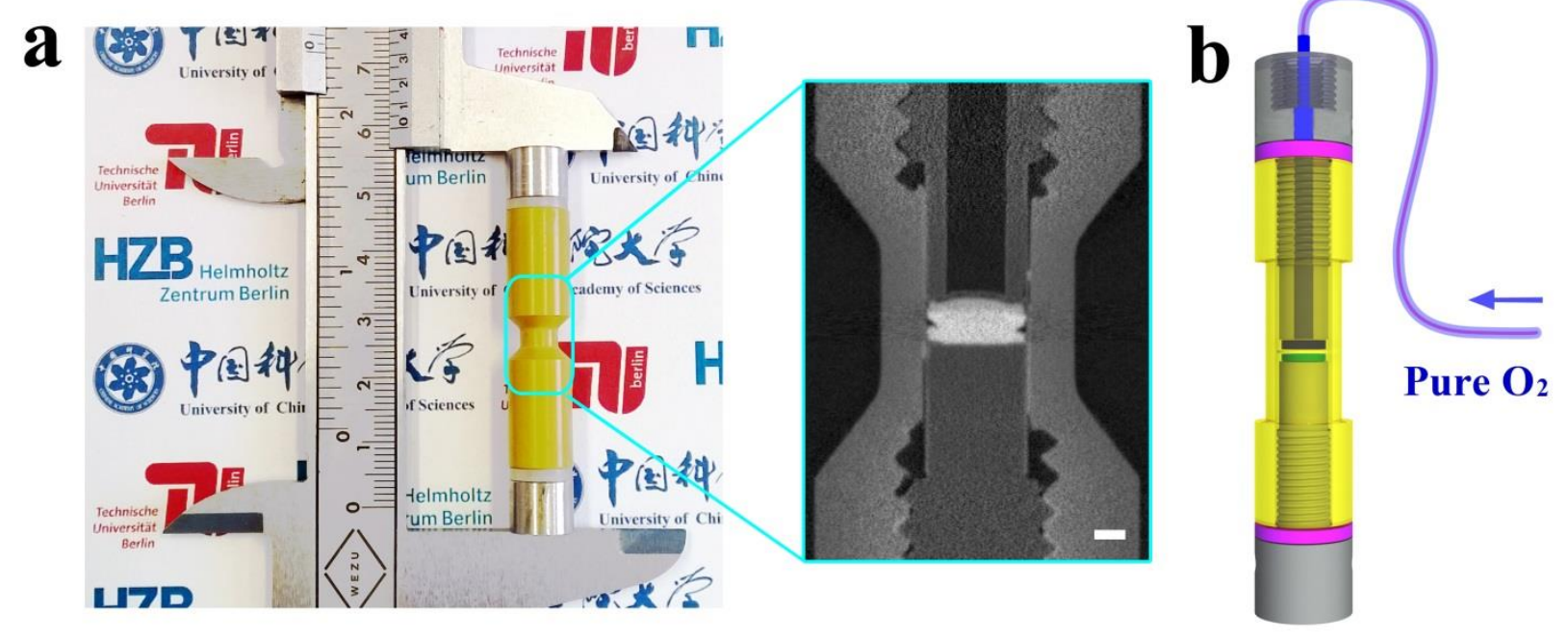

Figure 1 Photography and illustration of the customized tomography cell. a), the photography of the fabricated cell, the enlarged picture in the cyan rectangle shows the interior of cell No.2, measured by neutron tomography. The scale bar is $1 \mathrm{~mm}$. b), the schematic of the tomo-cell (connected to an oxygen tube by a drilling hole) consisting of a polyamide-imide housing (yellow), two screw (light grey), two sealing rings (pink), a porous separator (white) sandwiched between two electrodes (dark blue and green).

\section{Part 1 In situ monitoring morphological evolution of $\mathrm{Li}$ anode}

In part 1, a Li-O 2 cell (cell No.1, tomo-cell) has been measured by in situ synchrotron X-ray (EDDI Beamline at Bessy II, Berlin) tomography during the first discharge/recharge process and the obtained results are shown in Fig. 2. Fig. 2A provides the electrochemical curve of the cell cycled at the current density of $0.1 \mathrm{~mA} \cdot \mathrm{cm}^{-1}$. Fig. 2B selectively displays the internal morphological states of the cell during the electrochemical process. Marked red points in Fig. 2A match the corresponding internal states shown in the time-lapse images in Fig. 2B. Three datasets shown in Fig. 2B with time stamp of 00:15, 12:45 and 19:45 were chosen to demonstrate the 3D renderings reconstructed from the X-ray tomography measurements and they are shown in Fig. 2C-2E, respectively.

From the first panel of Fig. 2B (time 00:15), three key cell components, i.e., the carbon cathode, the glass fiber separator and the $\mathrm{Li}$ anode can be clearly observed. The original thickness of the $\mathrm{Li}$ anode was $\sim 244 \mu \mathrm{m}$ and that of the separator was $\sim 269 \mu \mathrm{m}$ (white and black arrows). During the cell operation, it can be seen from the rest panels in Fig. 2B that a porous-structuralized transition layer (PTL, see the yellow arrows in Fig. 2B) gradually developed on top of $\mathrm{Li}$ anode as a function of cycle time. Looking at the last panel of Fig. 2B (time stamp 19:45), one can see that the thickness of PTL has increased significantly to $\sim 158 \mu \mathrm{m}$. In accordance with the development of the PTL during the electrochemical cycling (Fig. 2A), the thickness of the original Li bulk has decreased to $\sim 115 \mu \mathrm{m}$ and a similar scenario of the separator decreased to $\sim 231 \mu \mathrm{m}$ can be found (white and 
black arrows in panel of 19:45). The red diamonds in Fig. 2B also clearly indicate the compression and elongation of the $\mathrm{Li}$ anode. The 3D views shown in Fig. 2C-E give comprehensive perspectives of the morphological changes observed in Fig. 2B. The whole in situ measurement can be found in the Supporting Movie.

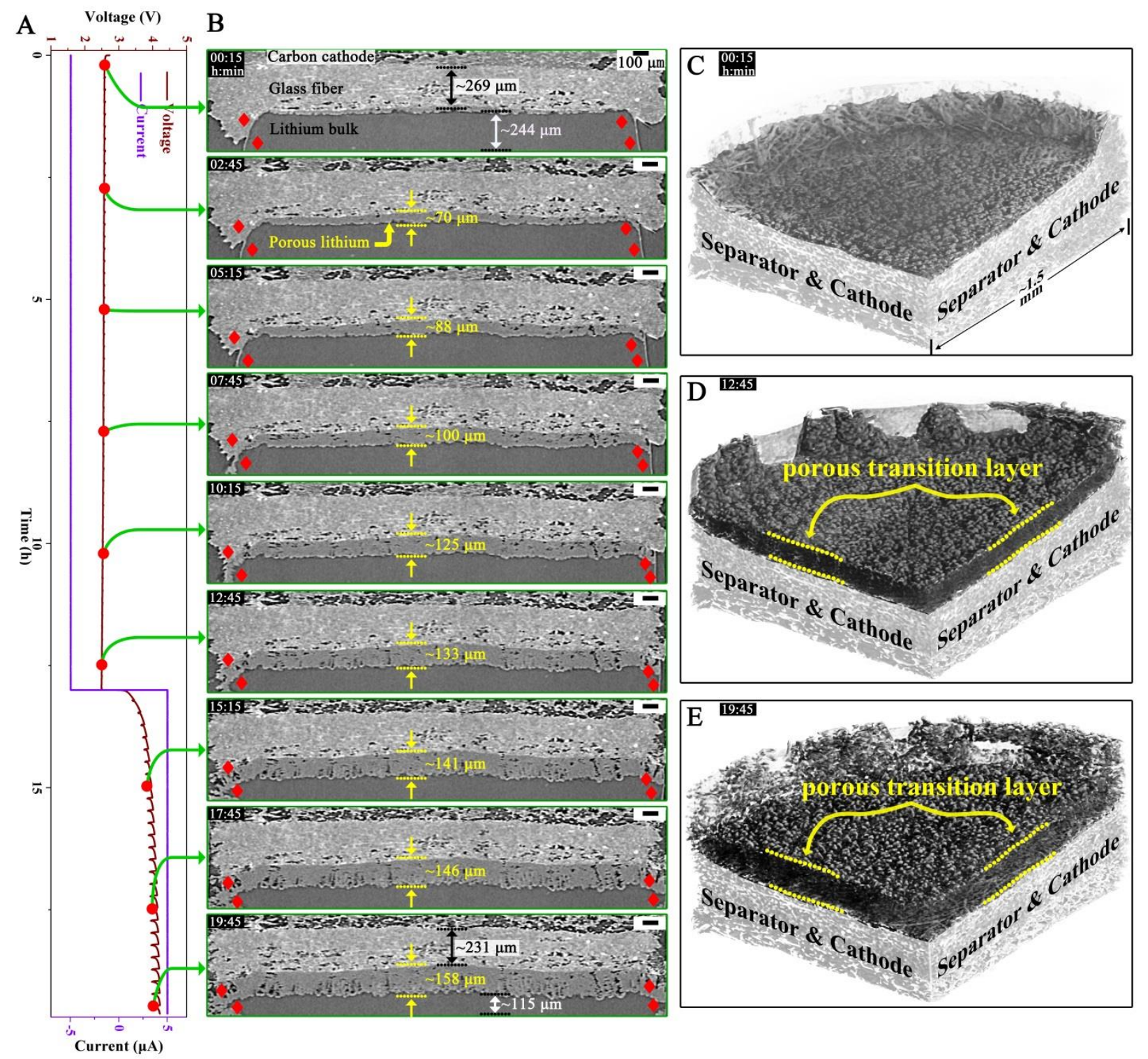

Figure 2 Electrochemical and morphological results of the cell No.1 in situ measured at EDDI beamline. A), the electrochemical cure. B), the morphological evolution of internal cell components of the $\mathrm{LOB}$ during the first discharge/recharge process. $\mathrm{C}$ )-E), the selected 3D demonstrations of the reconstructed datasets shown in panels in B with time stamp 00:15, 12:45 and 19:45. Note that the anode sides in 3D demonstrations in Figure 2C-E have been reversed downside up. 
The in situ characterization indicates unambiguously that the gradual development of the PTL is at the expanse of the original bulk Li during the electrochemical cycling (see the change of yellow and white arrows in Fig. 2B). Furthermore, it can be observed clearly that the PTL grows continuously during both discharge and charge process and the transformation from bulk Li to the observed PTL is irreversible due to the fact that the anode Li does not seemingly to regain its original bulk state during the recharge process (see the last four panels in Fig. 2B). Meanwhile, a large volume expansion accompanying with this irreversible transformation would generate sufficient force and exert it on the contacting separator. This has been confirmed by the observed volume contraction of the separator after the first cycle (compare black arrows in the first and last panel in Fig. 2B). In summary, the current in-situ characterization strongly indicates that the morphological transformation of anode Li from its original bulk state to the PTL structure is irreversible. Cells undergoing different cycle numbers are studied in part 2 and detailed post-mortem morphological/compositional analyses from the Swagelok LOBs are shown in part 3.

\section{Part 2 Ex situ characterizing the cycled Li anodes}

Currently 4 different cells (cell No. 2 to 5, tomo-cells, cycling routes are shown in the first column of Fig. 3) have been measured by both synchrotron X-ray (P05 beamline at DESY, Hamburg ${ }^{34}$ ) and neutron (V7 beamline at BER II, Berlin ${ }^{35}$ ) tomography after cycling without cell disassembly. For comparison, one uncycled cell (cell No.0, tomo-cell) was measured by a laboratory X-ray source and the result is shown in Fig. 3A1. The spatial resolution of the synchrotron X-ray measurement is $\sim 1.2 \mu \mathrm{m}$ and the reconstructed results are shown in the third column of Fig. 3, that of the neutron measurement is $\sim 13 \mu \mathrm{m}$ and the corresponding results are shown in the second column. Examples of 3D demonstrations reconstructed from the X-ray and neutron tomography measurements of the cell No.2 are shown in Fig. 3A2 and A3, respectively. More detailed information can be found in the Methods section. 

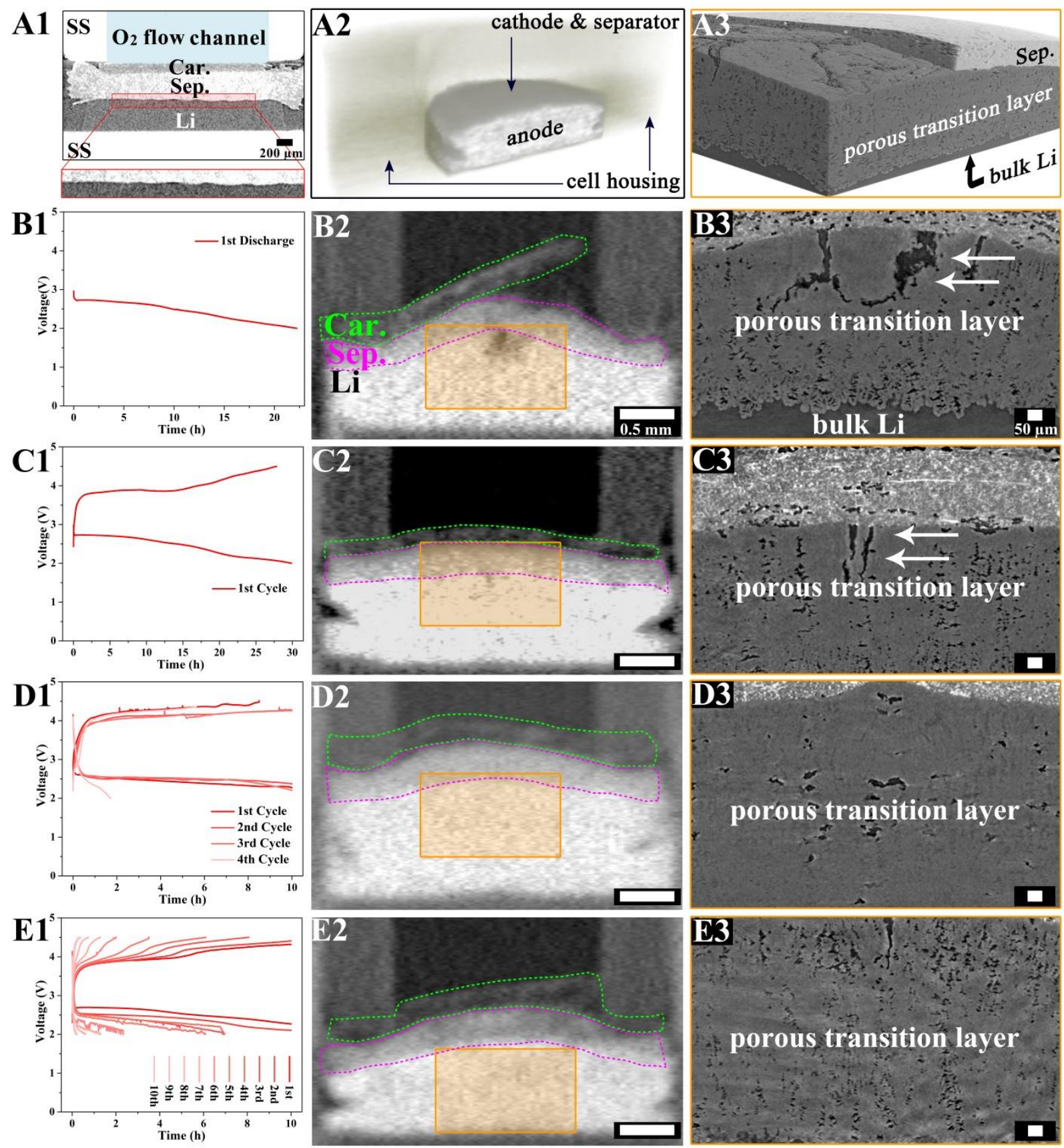

Figure 3 Electrochemical curves and inside views of the investigated LOBs by X-ray and neutron tomography. A1), inside view of the uncycled cell No.0 measured by a laboratory X-ray machine. The stainless steel (SS) current collect, the oxygen flow channel, the carbon (Car.) fiber cathode, the separator (Sep.) and the lithium (Li) anode have been labeled; A2) and A3), 3D demonstrations of the cell No.2 reconstructed from the X-ray and neutron measurements, representing the rest of the measurements; B1)-E1), the electrochemical curves; B2)-E2), the inside views of the neutron measurements; C3)-E3), the inside views of the X-ray measurements; B1)-B3), results of the cell 
No.2; C1)-C3), results of the cell No.3; D1)-D3), results of the cell No.4 and E1)-E3), results of the cell No.5. For more information, see Methods.

Compare the uncycled cell No.0 (inside view, Fig. 3 A1) with the other 4 cycled cells (inside views, B2-E2 and B3-E3), one can clearly observe the noticeable morphological changes of the cycled Li anodes. In Fig. 3B3, noticeable structural transformation of the Li anode after the first discharge (Fig. 3 B1) can be seen (see the bulk Li and the porous structure in Fig. 3B3). After the first cycle (Fig. 3C1) of the cell No.3, significant transformation can be observed in Fig. 3C3. This is in good agreement with the results observed in part 1 . With the increase of cycle numbers (from four cycles to ten cycles, shown in Fig. 3D1-E1), similar trend with greater extent of the morphological transformation can be observed (Fig. 3D3-E3). The higher degree of the morphological transformation after more cycles also suggests that this morphological change is irreversible because the cycled $\mathrm{Li}$ anodes do not regain their original bulk Li state after cycling. Considering the scenarios observed in part 1 , one may expect that the greater extent of the transformation of the Li anode and the accompanied huge volume expansion would generate higher degree of forces. Actually, from the neutron measurements shown in Fig. 3 B2-E2, it can be reasonably inferred that significant forces have been indeed generated during the volume change and they have pushed the separator and the carbon cathode into the drilling holes, where physical constrain is free. Lastly, correlating the morphological changes of the anode Li inside cell No.4 and No.5 (Fig. 3D3 and E3, respectively) to their electrochemical performances (Fig. 3D1 and E1, respectively), one can also rationally conclude that higher extent of Li transformation does relate closely to the more severely deteriorated electrochemical performance.

The results from the ex situ characterizations of the $\mathrm{Li}$ anodes in cycled LOBs are in good agreement with that obtained from part 1 and they further suggest that the morphological transformation of anode Li after electrochemical cycling is irreversible. Moreover, these results also indicate that the overall LOB electrochemical performance does relate closely to the state of the $\mathrm{Li}$ anode in a way that a higher extent of the irreversible transformation of $\mathrm{Li}$ anode leads to a higher level of performance degradation. This is clearly shown by the cell No.5 (Fig. 3E1-E3) in which the complete transformation of Li (Fig. 3E3) results in the ultimate cell failure (Fig. 3E1). On the basis of the works shown in part 1 and 2, one can safely conclude that the irreversible conversion of Li anode during electrochemical cycling contribute significantly to the degradation of the overall cell's electrochemical performance. The detailed post-mortem studies on the irreversibly transformed PTL structure from the original bulk Li anode are shown in part 3.

\section{Part 3 Further post-mortem analysis of Li anode through XRD, SEM and FTIR}

In order to identify the structure and constituent of PTL observed by the X-ray and neutron tomography, Li anodes of LOBs using swage-cells under different conditions were further 
investigated by post-mortem SEM, XRD and FTIR characterizations. Firstly, Li anodes undergoing different electrochemical conditions were studied. Fig. 4A displays the Li anodes harvested from the cell No.6 at certain state during the first discharge and Fig. 4B-F show the studies of the cycled Li anodes harvested from cells No.7 and No.8 after the first cycle and the tenth capacity-limited cycle, respectively. Cells No.6-8 (Swagelok cells) have been disassembled after electrochemical cycling for post-mortem characterizations. The electrochemical curves of these three cells are shown in SI Figure 1.

From Fig. 4A, it can be seen that the color of the anode Li was gradually converted from originally lustrous (pristine state) to finally lusterless dark-gray after $22 \mathrm{~h}$ discharge. Similar scenario was also found in cycled Li anodes after the first and tenth cycle, as shown in Fig. 4B1-D1. SEM characterizations were conducted to compare the cycled and the pristine Li anodes. Fig. 4B2-B4 show that the uncycled $\mathrm{Li}$ anode was relatively smooth. After the first cycle of cell No.7 (electrochemical curve shown in SI Figure 1B), the Li anode shows a rough and cracked surface, as displayed in Fig. 4C2 (white arrows). The corresponding cross-sectional view (Fig. 4C3) and the zoomed-in figure (Fig. 4C4) clearly indicate that the original bulk Li has transformed to the PTL structure. Similar discoveries were found in the Li anode after the tenth cycle of cell No.8 (electrochemical curve shown in SI Figure 1C), as shown in Fig. 4D2-D4 (Note the false coloring in C3 and D3, green for PTL and purple for bulk Li). Compare Fig. 4C3 and Fig. 4D3, one can also clearly observe that a higher degree of the irreversible transformation of anode $\mathrm{Li}$ (from $\sim 250 \mu \mathrm{m}$ to $\sim 440 \mu \mathrm{m}$ ) occurred after longer operation time (see SI Figure 1). These results are in good agreement with that obtained from the X-ray and neutron measurements (see part 1 and 2). Fig. 4E-F show the constituting components of the developed PTL determined by XRD and FTIR (two more cells of cell No.9, after the first discharge and cell No. 10 after the fourth cycle were measured together with cell No. 7-8. See more in Methods). From the XRD measurements (Fig. $4 \mathrm{E}$ ), one can clearly observe that after different electrochemical cycling conditions, new diffraction peaks of 2 theta $=20.47^{\circ}, 32.58^{\circ}, 33.75^{\circ}$, which can be assigned to $\mathrm{LiOH},{ }^{36-37}$ appeared in addition to the original Li meatal peaks at $36.19^{\circ}$ and $64.98^{\circ}$ (PDF card No. 15-0401). Moreover, one can also notice that the intensity of the Li diffraction peaks decreased strongly after the electrochemical cycling, probably due to the formation of the thick PTL. The FTIR results shown in Fig. 4F further imply the presence of $\mathrm{Li}_{2} \mathrm{CO}_{3}$ in addition to $\mathrm{LiOH}$. These compositional characterizations confirmed that the developed PTL is mainly consisted of $\mathrm{LiOH}$ and $\mathrm{Li}_{2} \mathrm{CO}_{3}$ (Note that $\mathrm{Li}$ cannot be detected, other by-product is hardly to be detected also due to the insufficient amount and amorphousness). 

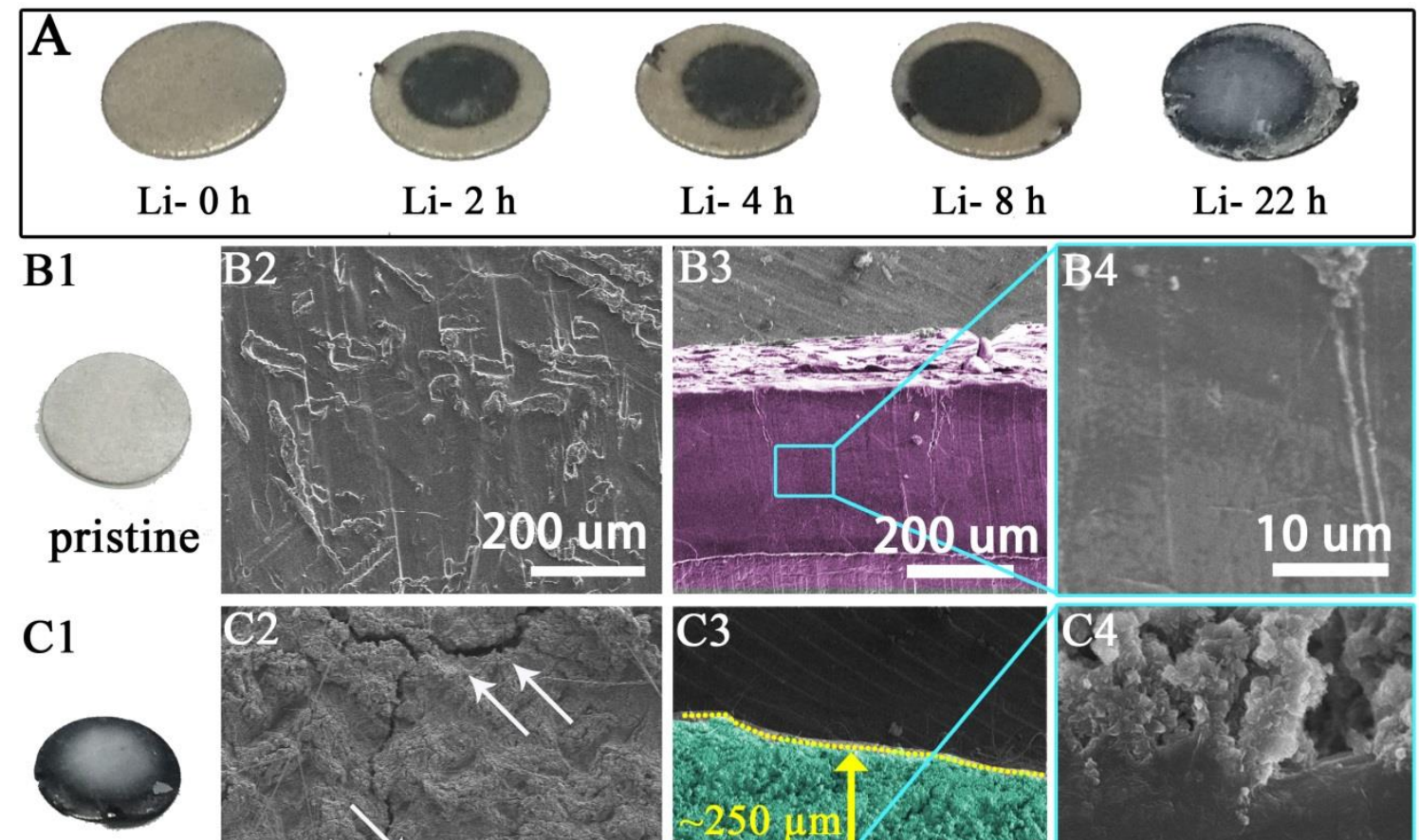

$1-\mathrm{D}-\mathrm{C}$
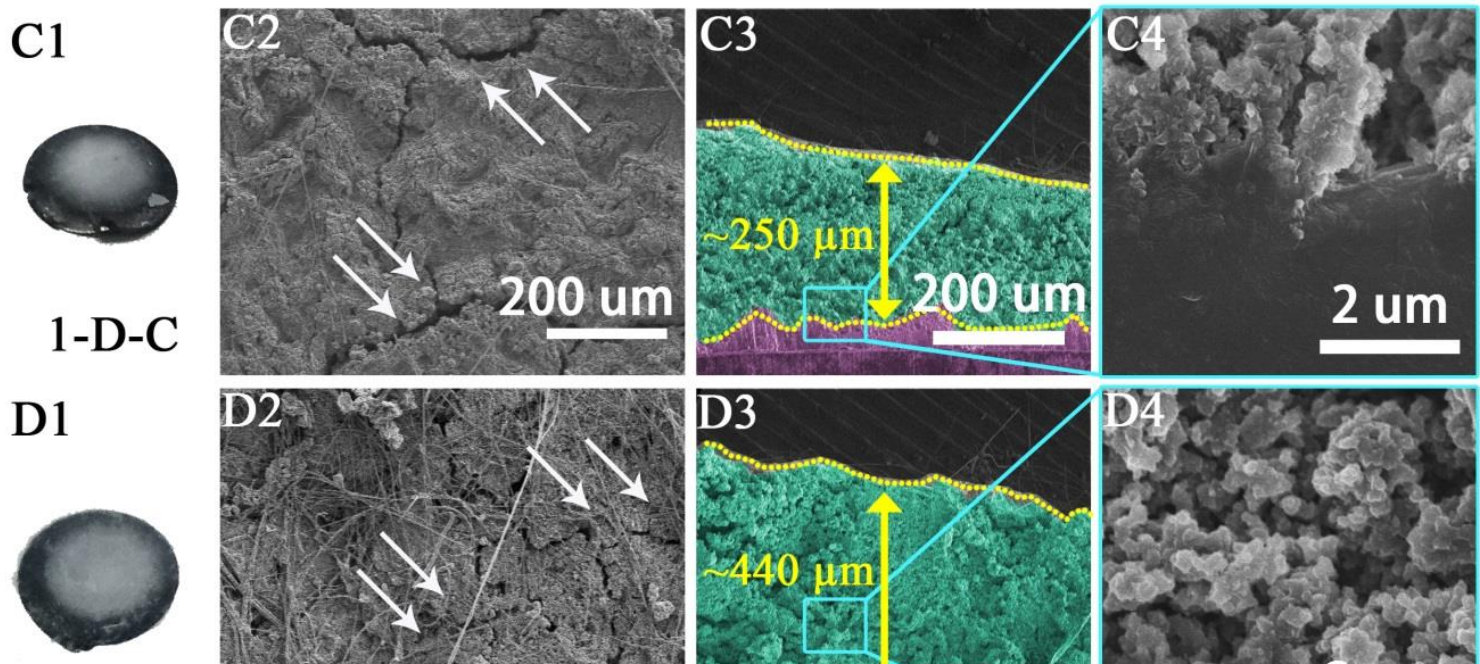

10-cyc
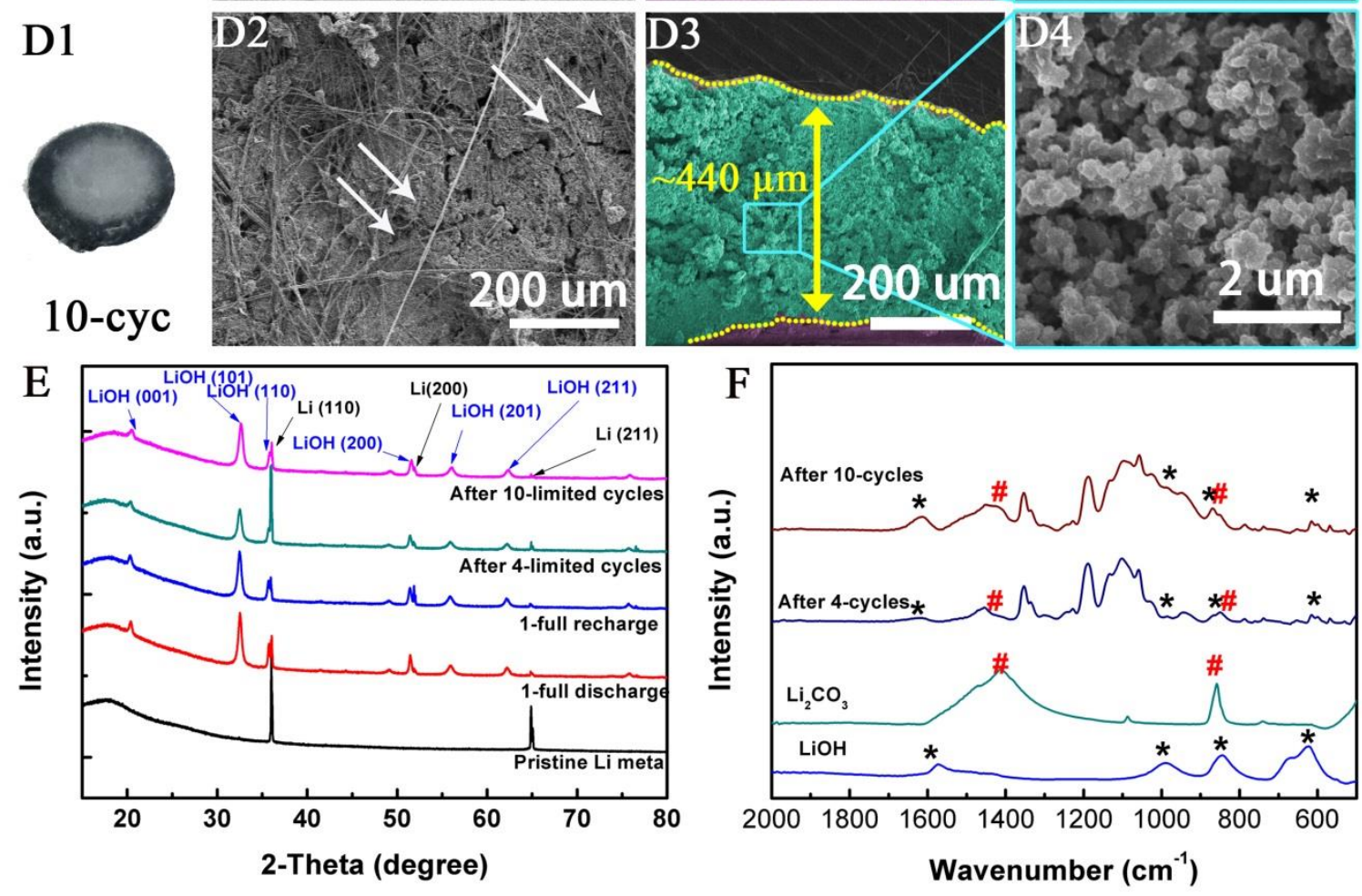

Figure 4 Post-mortem characterizations of Li anodes after different electrochemical conditions by SEM, XRD and FTIR. A), photographs of the Li anode harvested at different states during the first discharge. B1)-B4), photograph and SEM results of the uncycled Li anode. C1)-C4), photograph 
and SEM results of the cycled Li anode harvested from cell No.7 after the first cycle. D1)-D4), photograph and SEM results of the cycled Li harvested from cell No.8 after the tenth cycle. E) and F), XRD and FTIR patterns of the cycled Li anodes at different states. The electrochemical curves of cells No.6-10 are shown in SI Figure 1. See more details in the Methods section.

Secondly, Li anodes experiencing no electrochemical but chemical conditions were studied to gain a complementing and complementary understanding of the irreversible transformation of anode $\mathrm{Li}$ observed under electrochemical conditions. Fig. 5 provides the photographs, SEM and compositional results of the $\mathrm{Li}$ anode before and after immersion in $\mathrm{O}_{2}$ saturated electrolyte for 24h. From Fig. 5A, it is surprising to find that the color of the Li turns from originally bright to dark grey after immersion in $\mathrm{O}_{2}$ saturated electrolyte for $24 \mathrm{~h}$, similar to that shown in Fig. 4A. The SEM images shown in Fig. 5B-E further demonstrate that the original Li bulk (Fig. 5B, C) could be transformed into PTL structure (Fig. 5D, E) after $24 \mathrm{~h}$ in $\mathrm{O}_{2}$ saturated electrolyte without applying any electrochemical conditions. Apart from that, the XRD and FTIR measurements confirmed the presence of $\mathrm{LiOH}$ and $\mathrm{Li}_{2} \mathrm{CO}_{3}$, as shown in Fig. 5F-G. From this control experiment, one can conclude that the bulk $\mathrm{Li}$ anode is ready to be transformed to porous-structuralized transition layer structure under sole contact with oxygen and electrolyte. Thus, it is reasonable to suspect that the formation of the PTL starts once Li anode contacts with oxygen and electrolyte.
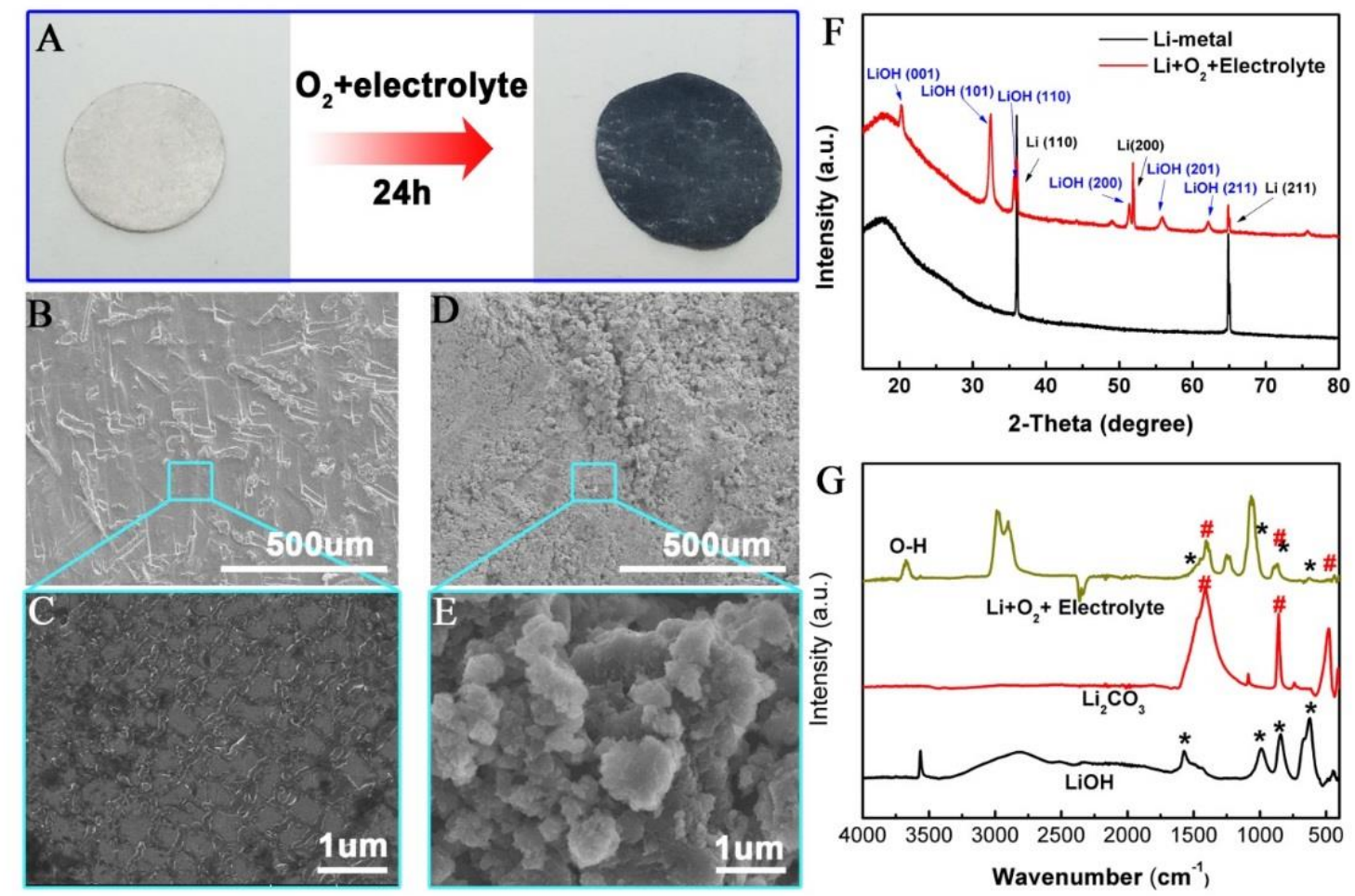

Figure 5 Characterizations of $\mathrm{Li}$ anodes after immersion in $\mathrm{O}_{2}$ saturated electrolyte for $24 \mathrm{~h}$ by SEM, XRD and FTIR. A), photographs of the Li anode before and after the immersion. B-C), SEM 
images of the pristine $\mathrm{Li}$ at different magnifications. D)-E), SEM images of the immersed $\mathrm{Li}$ at different magnifications. F)-G), XRD and FTIR patterns of the Li before and after the immersion.

The investigation of the $\mathrm{Li}$ metal undergoing non-electrochemical conditions provides complementing information to that of $\mathrm{Li}$ anode undergoing different electrochemical processes. These studies collectively suggest that the transformation of the bulk Li to the PTL structure occurs at least via 2 possible ways, i.e., the chemical way (path 1) and the electrochemical way (path 2), as schematically shown in Fig. 6A, B. From the chemical point of view, due to its high activity of $\mathrm{Li}$, almost all currently used electrolytes in non-aqueous LOBs exhibit various degree of degradation after their contact with $\mathrm{Li}^{38-39}$ Moreover, side reactions between $\mathrm{Li}$ and electrolyte can be further complicated by the participation of $\mathrm{O}_{2}$ transferred from the oxygen penetrable glass fiber separator. ${ }^{40}$ Trace amounts of water in either $\mathrm{O}_{2}$ or electrolyte can also result in the hydroxylation of $\mathrm{Li}$, contributing to the conversion reactions. ${ }^{41}$ The path 1 can perfectly explain the findings shown in Fig. 5. From the electrochemical point of view, the applied over-potential during LOB cycling may accelerate the decomposition of the electrolyte in presence of $\mathrm{Li}$ anode. ${ }^{42}$ Furthermore, it can facilitate the irreversible transformation of bulk $\mathrm{Li}$ anode by driving the reaction intermediates, redox mediators, additives and/or catalysts from cathode side to diffuse through the separators to the $\mathrm{Li}$ anode side, causing a series of chain side-reactions that have not been fully understood. ${ }^{43-45}$ Considering that those side-reactions occurring either chemically or electrochemically are highly irreversible during LOB operation, one can expect that a large amount of by-products/PTL would be accumulated on top of bulk $\mathrm{Li}$ anode after long-term cycling of LOBs. The process is schematically shown in Fig. 6C. This picture can fundamentally explain the development of the PTL transformed from the original bulk $\mathrm{Li}$ anode after different electrochemical cycling conditions observed through X-ray and neutron tomography measurements in part 1 and 2, together with the post-mortem SEM characterizations shown in part 3. 


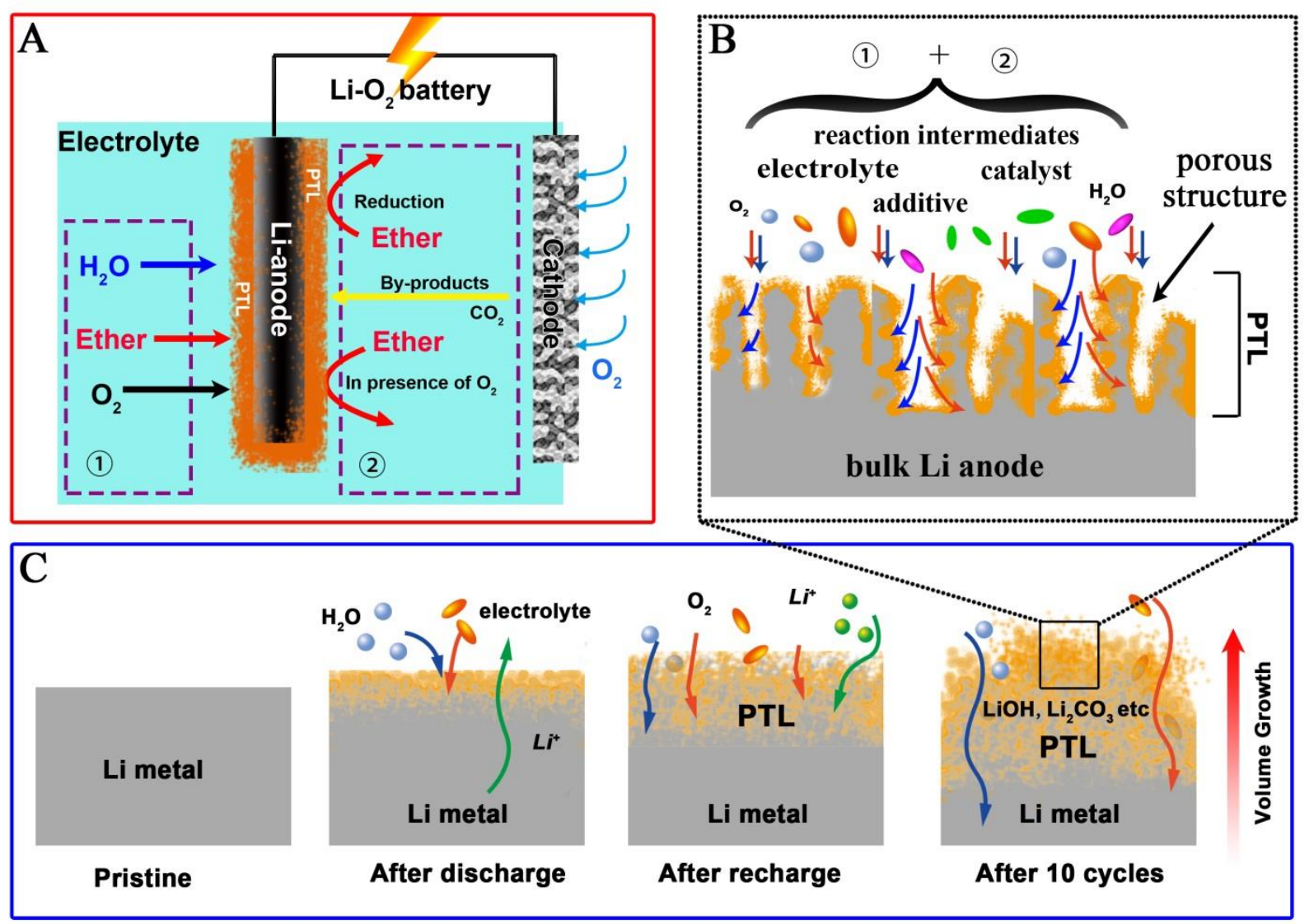

Figure 6 Schematic illustrations of the irreversible transformation of bulk Li anode in LOBs under different conditions. A) and B), two possible ways of the $\mathrm{Li}$ anode transformation in a $\mathrm{LOB}$ employing ether-based electrolyte, i.e., the chemical path (1) and the electrochemical path (2). C), the illustration of the morphological evolution of the gradual development of PTL at the expense of the original bulk Li anode during long-term electrochemical cycling condition.

The current findings of the irreversible transformation of the original bulk Li anode to PTL structure after electrochemical cycling characterized by X-ray and neutron tomography, together with post-mortem SEM are in good agreement with previously reported corrosion/degradation/irreversibility of cycled Li anode. ${ }^{46-47}$ They collectively suggest that the irreversible transformation of $\mathrm{Li}$ anode, which is closely associated with the irreversible sidereactions occurring chemically/electrochemically between $\mathrm{Li}$ and other components, would eventually result in cell death by the continuous exhaust/consumption of the cell components. ${ }^{48}$ Meanwhile, the significant volume expansion accompanying this irreversible transformation would generate sufficient force to deform/damage the cathode/separator, leading to the unprecedented collapse of the cathode integrity (Fig. 3B2) and contributing to the observed electrochemical performance deterioration. These currently observed irreversible morphological changes of inner cell components can thus be served as a direct indicator of the overall cell performance state. The governing role played by the irreversible transformation of Li anode in the 
failure mechanism of LOB performance during long-term operation is thus clearly identified. Other compelling corroboration of this dominating role played by Li anode has been shown by Jang et al. ${ }^{49}$ who have experimentally displayed that new cell assembled with used cathode and new $\mathrm{Li}$ anode functioned properly while new cell assembled with used $\mathrm{Li}$ anode and new cathode didn't. This has also been confirmed by Schroeder et al., who found that the failed LOB can be fully recovered to the same state before failure by solely replacing the used $\mathrm{Li}$ anode.$^{50} \mathrm{On}$ the other hand, Jang et al. discovered that the extent of the degradation of a LOB employing less amount of $\mathrm{Li}$ was more severe than that using sufficient amount during the investigation of the effects of the amount of $\mathrm{Li}$ used as anode on the overall performance behavior over extended cycling. ${ }^{51}$ These results provide supplementary and interesting insights into the role played by $\mathrm{Li}$ anode in determining the underlying LOB failure/degradation mechanism.

All in all, a combination of in situ X-ray tomography, ex situ X-ray and neutron tomography, postmortem SEM, XRD and FTIR analysis were employed to investigate the morphologic and compositional evolution of $\mathrm{Li}$ anode under various chemical/electrochemical conditions. It was found that 1) the active $\mathrm{Li}$ anode can be chemically deteriorated in $\mathrm{O}_{2}$ saturated electrolyte under non-electrochemical condition and the applied over-potential during electrochemical cycling facilitates the irreversible transformation of anode Li from original bulk Li to the PTL structure (part 3); 2) the extent of the irreversible transformation of anode Li increases in direct proportion to the LOB operation time and this transformation occurs during both discharge and charge process (part 1);3) the continuous irreversible transformation of anode Li during extended electrochemical cycling can not only gradually consume cell components but also cause detrimental damage to the integrity of the cathode side, resulting in the ultimate performance decay/ cell failure (part 2). Meaningful implications and potential future research directions that can be drawn on the basis of current report are discussed below.

Firstly, sufficient attentions have to be paid to the characterization of the Li anode in future LOB research activities. When scrutinizing through previously reported publications on LOBs, one can inevitably find that the role of the $\mathrm{Li}$ anode in the underlying degradation/failure mechanisms of LOBs has been largely neglected or unconsciously overlooked by vast majority of researchers due to either the limited access to non-destructive diagnostic tools or insufficient knowledge of understanding. ${ }^{52}$ Although several researchers have noticed the importance of $\mathrm{Li}$ anode and prosed to protect it by artificial protection layers ${ }^{53-54}$ using high-concentration electrolyte ${ }^{55}$ or lithium alloy, ${ }^{56}$ yet these reportedly improvements remain to be further corroborated due to the dramatic difference one can distinguish between the pristine Li bulk and the cycled porous Li structure in their presented SEM pictures (which sharing great similarities observed herein). Latest report in which the degradation/corrosion layer can be used to enhance the cyclability of LOB further challenges the current understanding and knowledge of the role played by the above-mentioned irreversible transformation. ${ }^{57}$ It is thus concluded that more and more future research attentions 
have to be paid to the fundamental investigation of the nature of the irreversible transformation of Li anode and its effect on overall cell performance.

Secondly, decreasing the extent of the irreversible transformation of anode Li may significantly enhance the LOB performance. From a practical point of view, long-term cycling of LOBs has been realized under certain conditions, such as capacity-limited cycling protocols (i.e., limited Li metal utilization within each cycle, often less than 10\% ), utilization of extra additives/catalysts, excess amount of $\mathrm{Li}$ anode and abundant quantity of electrolyte. ${ }^{27}$ Based on the current findings that the continuous and irreversible decompositions among the LOB key components can straightforwardly lead to cell failure, one can reasonably infer that the cycling life of LOBs can be somehow extended by providing them in sufficient richness. However, sustaining the cell components in sufficient richness can only seemingly extend the cycle life of LOBs but in reality is unfavorably practical. ${ }^{58}$ This is also true for the suggestion to improve the round-trip efficiency (CE) of LOB by replacing the electrochemically unstable Li metal by more stable materials but possessing high electropositivity (e.g., $\mathrm{LiFePO}_{4}, \sim 3.45 \mathrm{~V}$ vs. $\mathrm{Li} / \mathrm{Li}^{+}$) as lithium source. ${ }^{59}$ It is thus suggested that novel strategies that can fundamentally suppress/eliminate the irreversible sidereactions of anode Li are highly desirable.

Last but not least, the foundation for further R\&D of LOB technology aimed at practical application may be relied upon the lessons learned from the development of the state-of-the-art LIB technology. It is important to mention that the instability of the Li anode has been the bottleneck for the commercialization of LIBs during 1980s and the LIB technology thrives and prevails only after replacing the Li anode with a more comparatively stable and reversible carbon anode. ${ }^{60}$ As is now recognized from the work of many researchers in LOB community, the ability to cycle a LOB is not necessarily a proof that the reactions occurring within are electrochemically reversible. ${ }^{61}$ As a result, exploring the reversibility of anode $\mathrm{Li}$ is an important direction for future research activates, for it is clear that any kind of improvement on cathode, catalyst, and electrolyte cannot solely push LOB technology into commercialization as long as the essential Li anode cannot be electrochemically reversibly cycled. Apart from the LOB technology, the lessons from the LIB technology may also apply to other metal air battery technologies since their fundamental features share great similarities. Actually, the significant corrosion/degradation of sodium, ${ }^{62}$ potassium $^{63}$ and zinc metals ${ }^{64}$ in their corresponding metal air batteries have already been demonstrated.

\section{Methods}

Materials, cell assembly and electrochemical cycling procedures

The housing of the customized electrochemical cell, the polyamide-imide (Torlon), was purchased

from Drake plastics Europe. The LiTFSI (lithium bis(fluorosulfonyl)imide), TEGDME (Tetraglyme), Whatman® glass fiber GF/D separator and the Parafilm were purchased from Sigma 
Aldrich. The lithium and the PVDF (Polyvinylidenfluorid) binder was purchased from MTI Cor. USA. The carbon fiber paper (Toray carbon paper, TGP-H-60) was purchased from Toray Industries, Japan.

The catalyst of cathode was r-GO (reduced graphene oxide), prepared via the hydrothermal reduction of GO. The carbon fiber supported cathode was made of $80 \%$ rGO catalyst and $20 \%$ PVDF binder. The electrolyte is $1 \mathrm{M}$ LiTFSI dissolved in TEGDME (Tetraglyme). Water content of electrolyte was measured by K-F method and the result was less than $20 \mathrm{ppm}$. All tomography cells were assembled with $\sim 0.1 \mathrm{ml}$ electrolyte in a glove-box. During a tomo-cell assembly, the $\mathrm{Li}$ anode ( $2.5 \mathrm{~mm}$ diameter) was placed on top of the steel screw, followed by the separator ( $3 \mathrm{~mm}$ diameter) and the carbon fiber cathode ( $2.5 \mathrm{~mm}$ diameter). The steel screw with a drilling hole was in direct contact with the cathode. All Swagelok cells were assembled with $\sim 300 \mu$ electrolyte in a glove-box. During a swage-cell assembly, the Li anode (16 $\mathrm{mm}$ diameter) was placed on top of negative current collector, followed by the separator $(25 \mathrm{~mm}$ diameter) and the carbon fiber cathode ( $8 \mathrm{~mm}$ diameter). All cells were sealed firstly in the glove-box and then were connected to an oxygen tube after being taken out. Before electrochemical cycling, all cells have been flushed with oxygen for 3 hours.

Cell No. 1 has been cycled at $5 \mu \mathrm{A}$ between 2 and $5 \mathrm{~V}$. Cell No. 2 has been discharged to $2 \mathrm{~V}$ at $7 \mu \mathrm{A}$. Cell No. 3 has been discharged to $2 \mathrm{~V}$ and then charged to $4.5 \mathrm{~V}$ at $7 \mu \mathrm{A}$. Cell No.4 has been cycled under this condition: discharged to $2 \mathrm{~V}$ or for $10 \mathrm{~h}$ at $5 \mu \mathrm{A}$; charged to $4.5 \mathrm{~V}$ or for $10 \mathrm{~h}$ at $5 \mu \mathrm{A}$. Cell No. 5 has been cycled under this condition: discharged to $2 \mathrm{~V}$ or for $10 \mathrm{~h}$ at $7 \mu \mathrm{A}$; charged to $4.5 \mathrm{~V}$ or for $10 \mathrm{~h}$ at $7 \mu \mathrm{A}$. All tomography cells (cell No. 1-5) were galvanostaticlly cycled by IviumStat. After electrochemical cycling, tomography cells of No.2-5 were flushed with pure argon for at least 7 hours and then sealed by parafilm in the air. Tomography cells (No.2-5) were measured at P05 beamline and V7 beamline without disassembly. Cells No.6-10 are Swagelok cells. Cell No.6 has been discharged at $70 \mu \mathrm{A}$ for $22 \mathrm{~h}$. Cell No. 7 was cycled at $70 \mu \mathrm{A}$ between 2 and $4.5 \mathrm{~V}$ for one cycle. Cell No.8 was cycled at $50 \mu \mathrm{A}$ between 2 and $4.5 \mathrm{~V}$ for 10 cycles with limited capacity of $500 \mu \mathrm{Ah}$. Cell No.9 has been discharged at $70 \mu \mathrm{A}$ for $30 \mathrm{~h}$. Cell No. 10 was cycled at $50 \mu \mathrm{A}$ between 2 and $4.5 \mathrm{~V}$ for 4 cycles with limited capacity of $500 \mu \mathrm{Ah}$. All Swagelok cells (cell No. 6-10) were galvanostaticlly cycled by LAND CT2001A and they were disassembled after the electrochemical cycling for post-mortem XRD, SEM and FTIR characterizations.

\section{$X$-ray and neutron measurements and data processing}

For cell No.0, it has been measured by a laboratory X-ray machine located at the HelmholtzZentrum Berlin. The important parameters are: the voltage and current of the X-ray tube are $60 \mathrm{KV}$ and $166 \mu \mathrm{A}$; the source-to-object distance is $58 \mathrm{~mm}$; the source-to-detector distance is $500 \mathrm{~mm}$; the resultant pixel resolution is $\sim 5.8 \mu \mathrm{m}$.

The in situ measurement presented in part 1 was conducted at the EDDI beamline, Bessy II, Berlin. The white synchrotron beam generated by the 7T-Wiggler, possessing energies from 6 to $120 \mathrm{KeV}$ was used in current. The detector system is comprised of a $200 \mu \mathrm{m}$ thick LuAG:Ce scintillator, a 
Schneider Optics macro lens with a magnifying factor of $\sim 4.4$, a PCO DIMAX high speed camera (2016×2016 pixels) equipped with a CMOS chip that is kept out of the direct beam by using a mirror (white beam optic). The field of view is $4 \times 4 \mathrm{~mm}^{2}$ (length $\times$ height). The battery was mounted on the rotation table and was remotely controlled by a potentiostat within the beamline hutch. Tomography measurement was conducted during the electrochemical cycling every 15 minutes. Each measurement took around 90 seconds and the achieved pixel size was $\sim 2.5 \mu \mathrm{m}$. For measurements conducted at the P05 beamline. The synchrotron beam energy was firstly monochromatized to $25 \mathrm{KeV}$ using a double multilayer monochromator (DMM). A CdWO 4 single crystal scintillator of $100 \mu \mathrm{m}$ thickness was used to convert the X-ray to visible light. A fast CMOS camera that was kept out of the direct beam by using a mirror was used. 2400 projections within a $180^{\circ}$ battery rotation were recorded with the exposure time of $0.5 \mathrm{~s}$. The achieved spatial resolution was $\sim 0.645 \mu \mathrm{m}$. It has to be noted that for samples measured here, a binning process of 2 by 2 was used when reconstructing the datasets due to the high noise ratio. As a result, the final pixel resolution is $\sim 1.29 \mu \mathrm{m}$.

For neutron measurements, the V7 beamline what provides neutrons with wavelengths between 2 and $6 \AA$ with a maximum at $3 \AA$ was used. The detector system was based on a CCD camera integrated in a light-tight box comprising a scintillator screen and a lens system projecting the image from the scintillator via a mirror onto the CCD chip. The 16 bit CCD camera used (Andor DW-436N-BV) has a Peltier-cooled chip with $2048 \times 2048$ pixels. During tomography, 500 projections were recorded during $360^{\circ}$ rotation. The pixel resolution achieved was $\sim 13 \mu \mathrm{m}$.

The raw tomography data from the laboratory X-ray instrument was processed using Octopus Reconstruction (8.9). The raw tomography data from P05 and V7 beamline were processed using in-house reconstruction software programmed in IDL 8.2, ImageJ and Octopus Reconstruction (8.9). The data was first normalized, de-noised and in the neutron data reconstruction case, filtered. Then the filtered back projection was used for final reconstruction. 3D demonstrations shown in Fig. 2 and Fig. 3 were generated using VGStudio MA 3.0.

\section{Post-mortem characterization of cycled Li anodes}

In order prevent the cycled Li anode from the air, all the Swagelok cells were disassembled in an Ar-filled glovebox and the harvested $\mathrm{Li}$ anodes were packaged in glass holder with $8 \mu \mathrm{m}$ thick Kapton film window.

$\mathrm{X}$-ray diffraction (XRD) patterns were recorded on a Rigaku Smartlab powder diffractometer with $\mathrm{Cu} \mathrm{K} \alpha$ radiation $\left(\lambda=0.154 \mathrm{~nm}, 9 \mathrm{~kW}\right.$ ), $2 \theta$ ranging from 20 to $80^{\circ}$. SEM images were carried out on Hitachi SU8010 with an acceleration voltage of $5 \mathrm{kV}$, work distance of $8 \mathrm{~mm}$. FTIR was carried out on Bruker VERTEX 80 with ATR mode in Ar atmosphere.

\section{Author Information}

F.S.*, R.G.* and D.Z.* contribute equally to this work. 
Fu Sun, Henning Markötter and Ingo Manke designed the cell. Fu Sun, Rui Gao, Kang Dong and Dong Zhou assembled, tested and measured the cells. Andre Hilger, Markus Osenberg, Peter Maria Bieker and Henning Markötter aided in synchrotron characterizations and the discussion of results. Fu Sun and Nikolay Kardjilov measured and analyzed the neutron measurement. Rui Gao and Xiangfeng Liu characterized and analyzed the post-mortem measurements. Fu Sun, Rui Gao and Dong Zhou composed the manuscript. All authors contributed to the data interpretation and the discussion of the results.

\section{Corresponding author}

Fu Sun: $\quad$ fu.sun@helmholtz-berlin.de or sunfu1998@gmail.com

ORCID ID: https://orcid.org/0000-0001-6787-6988

Xiangfeng Liu: liuxf@ucas.ac.cn

Dong Zhou: dong.zhou@ uni-muenster.de

\section{Notes}

The authors declare no competing financial interest.

\section{Acknowledges}

We thank engineer Norbert Beck for fabricating the beamline battery. We thank DESY for providing us valuable beam time and Dr. Fabian Wilde for his valuable assistance at beamlines. This work is sponsored by China Scholarship Council and is partially funded by the German Research Foundation, DFG (Project No. MA 5039/4-1). This work was also supported by Beijing Natural Science Foundation (Grant No. 2182082), National Natural Science Foundation of China (Grant No. 11575192), the Scientific Instrument Developing Project (Grant No.ZDKYYQ20170001), the International Partnership Program (Grant No. 211211KYSB20170060) and "Hundred Talents Project" of the Chinese Academy of Sciences.

\section{References}

(1) Lu, J.; Li, L.; Park, J.-B.; Sun, Y.-K.; Wu, F.; Amine, K. Aprotic and Aqueous Li-O-2 Batteries. Chem. Rev. 2014, 114, 5611-5640.

(2) Bruce, P. G.; Freunberger, S. A.; Hardwick, L. J.; Tarascon, J.-M. Li-O-2 and Li-S Batteries with High Energy Storage. Nat. Mater. 2012, 11, 19-29.

(3) Li, F.; Zhang, T.; Zhou, H. Challenges of Non-Aqueous Li-O-2 Batteries: Electrolytes, Catalysts, and Anodes. Energy Environ. Sci. 2013, 6, 1125-1141.

(4) Hummelshoj, J. S.; Luntz, A. C.; Norskov, J. K. Theoretical Evidence for Low Kinetic Overpotentials in Li-O-2 Electrochemistry. J. Chem. Phys. 2013, 138. 
(5) Kwabi, D. G.; Ortiz-Vitoriano, N.; Freunberger, S. A.; Chen, Y.; Imanishi, N.; Bruce, P. G.; Shao-Horn, Y. Materials Challenges in Rechargeable Lithium-Air Batteries. Mrs. Bull. 2014, $39,443-452$.

(6) Wang, L.; Pan, J.; Zhang, Y.; Cheng, X.; Liu, L.; Peng, H. A Li-Air Battery with Ultralong Cycle Life in Ambient Air. Adv. Mater. 2018, 30, 1704378-1704384.

(7) Gao, R.; Li, Z.; Zhang, X.; Zhang, J.; Hu, Z.; Liu, X. Carbon-Dotted Defective Coo with Oxygen Vacancies: A Synergetic Design of Bifunctional Cathode Catalyst for Li-O2 Batteries. ACS Catal. 2016, 6, 400-406.

(8) Wong, R. A.; Yang, C.; Dutta, A.; O, M.; Hong, M.; Thomas, M. L.; Yamanaka, K.; Ohta, T.; Waki, K.; Byon, H. R. Critically Examining the Role of Nanocatalysts in Li-O2 Batteries: Viability toward Suppression of Recharge Overpotential, Rechargeability, and Cyclability. ACS Energy Lett. 2018, 3, 592-597.

(9) Yu, W.; Wang, H.; Hu, J.; Yang, W.; Qin, L.; Liu, R.; Li, B.; Zhai, D.; Kang, F. Molecular Sieve Induced Solution Growth of Li2o2 in the Li-O2 Battery with Largely Enhanced Discharge Capacity. ACS Appl. Mater. Interfaces 2018, 10, 7989-7995.

(10) Liu, R.; Lei, Y.; Yu, W.; Wang, H.; Qin, L.; Han, D.; Yang, W.; Zhou, D.; He, Y.; Zhai, D.; et al. Achieving Low Overpotential Lithium - Oxygen Batteries by Exploiting a New Electrolyte Based on N,N' -Dimethylpropyleneurea. ACS Energy Lett. 2017, 2, 313-318. (11) Ulissi, U.; Elia, G. A.; Jeong, S.; Mueller, F.; Reiter, J.; Tsiouvaras, N.; Sun, Y. K.; Scrosati, B.; Passerini, S.; Hassoun, J. Low - Polarization Lithium - Oxygen Battery Using [Deme][Tfsi] Ionic Liquid Electrolyte. ChemSusChem 2018, 11, 229-236.

(12) Chamaani, A.; Safa, M.; Chawla, N.; El-Zahab, B. Composite Gel Polymer Electrolyte for Improved Cyclability in Lithium-Oxygen Batteries. ACS Appl. Mater. Interfaces 2017, 9 , 33819-33826.

(13) Lu, Y.-C.; Crumlin, E. J.; Veith, G. M.; Harding, J. R.; Mutoro, E.; Baggetto, L.; Dudney, N. J.; Liu, Z.; Shao-Horn, Y. In Situ Ambient Pressure X-Ray Photoelectron Spectroscopy Studies of Lithium-Oxygen Redox Reactions. Sci. Rep. 2012, 2, 715-721.

(14) Lin, D.; Liu, Y.; Cui, Y. Reviving the Lithium Metal Anode for High-Energy Batteries. Nat. Nanotechnol. 2017, 12, 194-206.

(15) Safanama, D.; Adams, S. Flexible Light-Weight Lithium-Ion-Conducting InorganicOrganic Composite Electrolyte Membrane. ACS Energy Lett. 2017, 2, 1130-1136.

(16) Gao, X.; Chen, Y.; Johnson, L. R.; Jovanov, Z. P.; Bruce, P. G. A Rechargeable LithiumOxygen Battery with Dual Mediators Stabilizing the Carbon Cathode. Nat. Energy. 2017, 2, 17118-17125.

(17) Qiao, Y.; He, Y.; Wu, S.; Jiang, K.; Li, X.; Guo, S.; He, P.; Zhou, H. Mof-Based Separator in an Li-O2 Battery: An Effective Strategy to Restrain the Shuttling of Dual Redox Mediators. ACS Energy Lett. 2018, 3, 463-468.

(18) Zhu, Y. G.; Wang, X.; Jia, C.; Yang, J.; Wang, Q. Redox-Mediated Orr and Oer Reactions: Redox Flow Lithium Oxygen Batteries Enabled with a Pair of Soluble Redox Catalysts. ACS Catal. 2016, 6, 6191-6197.

(19) Qiao, Y.; Wu, S.; Sun, Y.; Guo, S.; Yi, J.; He, P.; Zhou, H. Unraveling the Complex Role of Iodide Additives in Li-O2 Batteries. ACS Energy Lett. 2017, 2, 1869-1878.

(20) Schafzahl, B.; Mourad, E.; Schafzahl, L.; Petit, Y. K.; Raju, A. R.; Thotiyl, M. O.; Wilkening, M.; Slugovc, C.; Freunberger, S. A. Quantifying Total Superoxide, Peroxide, and Carbonaceous Compounds in Metal-O2 Batteries and the Solid Electrolyte Interphase. ACS Energy Lett. 2018, 3, 170-176. 
(21) Ganapathy, S.; Adams, B. D.; Stenou, G.; Anastasaki, M. S.; Goubitz, K.; Miao, X.-F.; Nazar, L. F.; Wagemaker, M. Nature of Li2o2 Oxidation in a Li-O2 Battery Revealed by Operando X-Ray Diffraction. J. Am. Chem. Soc. 2014, 136, 16335-16344.

(22) Shin, H.-J.; Kwak, W.-J.; Aurbach, D.; Sun, Y.-K. Large-Scale Li $\square$ O2 Pouch Type Cells for Practical Evaluation and Applications. Adv. Funct. Mater. 2017, 27, 1605500.

(23) Liu, P.; Han, J.; Guo, X.; Ito, Y.; Yang, C.; Ning, S.; Fujita, T.; Hirata, A.; Chen, M. Operando Characterization of Cathodic Reactions in a Liquid-State Lithium-Oxygen MicroBattery by Scanning Transmission Electron Microscopy. Sci. Rep. 2018, 8, 3134.

(24) Olivares-Marín, M.; Sorrentino, A.; Lee, R.-C.; Pereiro, E.; Wu, N.-L.; Tonti, D. Spatial Distributions of Discharged Products of Lithium-Oxygen Batteries Revealed by Synchrotron XRay Transmission Microscopy. Nano Lett. 2015, 15, 6932-6938.

(25) Ma, Z.; Yuan, X.; Li, L.; Ma, Z.-F.; Wilkinson, D. P.; Zhang, L.; Zhang, J. A Review of Cathode Materials and Structures for Rechargeable Lithium-Air Batteries. Energy Environ. Sci. 2015, 8, 2144-2198.

(26) Vegge, T.; Garcia-Lastra, J. M.; Siegel, D. J. Lithium-Oxygen Batteries: At a Crossroads? Curr. Opin. Electrochem 2017, 6, 100-107.

(27) Zhang, W.; Shen, Y.; Sun, D.; Huang, Z.; Huang, Y. Objectively Evaluating the Cathode Performance of Lithium - Oxygen Batteries. Adv. Energy Mater. 2017, 7, 1602938-1602954.

(28) Nanda, J.; Bilheux, H.; Voisin, S.; Veith, G. M.; Archibald, R.; Walker, L.; Allu, S.;

Dudney, N. J.; Pannala, S. Anomalous Discharge Product Distribution in Lithium-Air Cathodes. J. Phys. Chem. C 2012, 116, 8401-8408.

(29) Shui, J.-L.; Okasinski, J. S.; Kenesei, P.; Dobbs, H. A.; Zhao, D.; Almer, J. D.; Liu, D.-J. Reversibility of Anodic Lithium in Rechargeable Lithium-Oxygen Batteries. Nat. Commun. 2013, 4, 2255-2262.

(30) Sun, F.; Zielke, L.; Markötter, H.; Hilger, A.; Zhou, D.; Moroni, R.; Zengerle, R.; Thiele, S.; Banhart, J.; Manke, I. Morphological Evolution of Electrochemically Plated/Stripped Lithium Microstructures Investigated by Synchrotron X-Ray Phase Contrast Tomography. ACS Nano 2016, 10, 7990-7997.

(31) Sun, F.; Moroni, R.; Dong, K.; Markötter, H.; Zhou, D.; Hilger, A.; Zielke, L.; Zengerle, R.; Thiele, S.; Banhart, J.; et al. Study of the Mechanisms of Internal Short Circuit in a Li/Li Cell by Synchrotron X-Ray Phase Contrast Tomography. ACS Energy Lett. 2017, 2, 94-104.

(32) Sun, F.; Osenberg, M.; Dong, K.; Zhou, D.; Hilger, A.; Jafta, C. J.; Risse, S.; Lu, Y.; Markötter, H.; Manke, I. Correlating Morphological Evolution of Li Electrodes with Degrading Electrochemical Performance of Li/Licoo2 and Li/S Battery Systems: Investigated by Synchrotron X-Ray Phase Contrast Tomography. ACS Energy Lett. 2018, 3, 356-365.

(33) Banhart, J.; Borbély, A.; Dzieciol, K.; Garcia-Moreno, F.; Manke, I.; Kardjilov, N.; Kaysser-Pyzalla, A. R.; Strobl, M.; Treimer, W. X-Ray and Neutron Imaging - Complementary Techniques for Materials Science and Engineering. Int. J. Mater. Res. 2010, 101, 1069-1079.

(34) Wilde, F.; Ogurreck, M.; Greving, I.; Hammel, J. U.; Beckmann, F.; Hipp, A.; Lottermoser, L.; Khokhriakov, I.; Lytaev, P.; Dose, T.; et al. Micro-Ct at the Imaging Beamline P05 at Petra Iii. AIP Conf. Proc. 2016, 1741, 030035-030039.

(35) Sun, F.; Markötter, H.; Manke, I.; Hilger, A.; Alrwashdeh, S. S.; Kardjilov, N.; Banhart, J. Complementary X-Ray and Neutron Radiography Study of the Initial Lithiation Process in Lithium-Ion Batteries Containing Silicon Electrodes. Appl. Surf. Sci. 2017, 399, 359-366. 
(36) Assary, R. S.; Lu, J.; Du, P.; Luo, X.; Zhang, X.; Ren, Y.; Curtiss, L. A.; Amine, K. The Effect of Oxygen Crossover on the Anode of a Li-O2battery Using an Ether-Based Solvent: Insights from Experimental and Computational Studies. ChemSusChem 2013, 6, 51-55.

(37) Zhang, X.; Zhang, Q.; Wang, X. G.; Wang, C.; Chen, Y. N.; Xie, Z.; Zhou, Z. An Extremely Simple Method for Protecting Lithium Anodes in Li-O2 Batteries. Angew Chem Int Ed Engl 2018.

(38) Nasybulin, E. N.; Xu, W.; Mehdi, B. L.; Thomsen, E.; Engelhard, M. H.; Massé, R. C.; Bhattacharya, P.; Gu, M.; Bennett, W.; Nie, Z.; et al. Formation of Interfacial Layer and LongTerm Cyclability of Li-O2 Batteries. ACS Appl. Mater. Interfaces 2014, 6, 14141.

(39) Nasybulin, E. N.; Xu, W.; Mehdi, B. L.; Thomsen, E.; Engelhard, M. H.; Massé, R. C.; Bhattacharya, P.; Gu, M.; Bennett, W.; Nie, Z.; et al. Formation of Interfacial Layer and LongTerm Cyclability of Li-O2 Batteries. ACS Appl. Mater. Interfaces 2014, 6, 14141-14151.

(40) Lee, H.; Lee, D. J.; Lee, J.-N.; Song, J.; Lee, Y.; Ryou, M.-H.; Park, J.-K.; Lee, Y. M. Chemical Aspect of Oxygen Dissolved in a Dimethyl Sulfoxide-Based Electrolyte on Lithium Metal. Electrochim. Acta 2014, 123, 419-425.

(41) Kraytsberg, A.; Ein-Eli, Y. Review on Li-Air Batteries-Opportunities, Limitations and Perspective. J. Power Sources 2011, 196, 886-893.

(42) Zhuang, G. V.; Yang, H.; Blizanac, B.; Philip N. Ross, J. A Study of Electrochemical Reduction of Ethylene and Propylene Carbonate Electrolytes on Graphite Using Atr-Ftir Spectroscopy. Electrochem. Solid-State Lett. 2005, 8, A441-A445.

(43) Tan, P.; Jiang, H. R.; Zhu, X. B.; An, L.; Jung, C. Y.; Wu, M. C.; Shi, L.; Shyy, W.; Zhao, T. S. Advances and Challenges in Lithium-Air Batteries. Appl. Energ. 2017, 204, 780-806.

(44) Aurbach, D.; Zinigrad, E.; Cohen, Y.; Teller, H. A Short Review of Failure Mechanisms of Lithium Metal and Lithiated Graphite Anodes in Liquid Electrolyte Solutions. Solid State Ion. 2002, 148, 405-416.

(45) McCloskey, B. D.; Speidel, A.; Scheffler, R.; Miller, D. C.; Viswanathan, V.; Hummelshøj, J. S.; Nørskov, J. K.; Luntz, A. C. Twin Problems of Interfacial Carbonate Formation in Nonaqueous Li-O2 Batteries. J. Phys. Chem. Lett. 2012, 3, 997-1001.

(46) Jang, I. C.; Ida, S.; Ishihara, T. Lithium Depletion and the Rechargeability of Li-O2 Batteries in Ether and Carbonate Electrolytes. ChemElectroChem 2015, 2, 1380-1384.

(47) Huang, Z.; Ren, J.; Zhang, W.; Xie, M.; Li, Y.; Sun, D.; Shen, Y.; Huang, Y. Protecting the Li-Metal Anode in a Li-O2 Battery by Using Boric Acid as an Sei-Forming Additive. Adv Mater 2018, e1803270.

(48) Ha, S.; Kim, Y.; Koo, D.; Ha, K.-H.; Park, Y.; Kim, D.-M.; Son, S.; Yim, T.; Lee, K. T. Investigation into the Stability of Li Metal Anodes in Li-O2 Batteries with a Redox Mediator. $J$. Mater. Chem. A 2017, 5, 10609-10621.

(49) Jang, I. C.; Ida, S.; Ishihara, T. Li Utilization and Cyclability of Li-O2 Rechargeable Batteries Incorporating a Mesoporous Pd/B-Mno2 Air Electrode. Electrochemistry 2014, 82, 267-272.

(50) Schroeder, M. A.; Pearse, A. J.; Kozen, A. C.; Chen, X.; Gregorczyk, K.; Han, X.; Cao, A.; Hu, L.; Lee, S. B.; Rubloff, G. W.; et al. Investigation of the Cathode-Catalyst-Electrolyte Interface in Aprotic Li-O2 Batteries. Chem. Mater. 2015, 27, 5305-5313.

(51) Jang, I. C.; Hidaka, Y.; Ishihara, T. Li Metal Utilization in Lithium Air Rechargeable Batteries. J. Power Sources 2013, 244, 606-609. 
(52) Schröder, D.; Bender, C. L.; Osenberg, M.; Hilger, A.; Manke, I.; Janek, J. Visualizing Current-Dependent Morphology and Distribution of Discharge Products in Sodium-Oxygen Battery Cathodes. Sci. Rep. 2016, 6, 24288.

(53) Zhu, J.; Yang, J.; Zhou, J.; Zhang, T.; Li, L.; Wang, J.; Nuli, Y. A Stable OrganicInorganic Hybrid Layer Protected Lithium Metal Anode for Long-Cycle Lithium-Oxygen Batteries. J. Power Sources 2017, 366, 265-269.

(54) Xu, J. J.; Liu, Q. C.; Yu, Y.; Wang, J.; Yan, J. M.; Zhang, X. B. In Situ Construction of Stable Tissue - Directed/Reinforced Bifunctional Separator/Protection Film on Lithium Anode for Lithium-Oxygen Batteries. Adv. Mater. 2017, 29, 1606552-1606558.

(55) Liu, B.; Xu, W.; Yan, P.; Sun, X.; Bowden Mark, E.; Read, J.; Qian, J.; Mei, D.; Wang, C. M.; Zhang, J. G. Enhanced Cycling Stability of Rechargeable Li - O2 Batteries Using High Concentration Electrolytes. Adv. Funct. Mater. 2016, 26, 605-613.

(56) Elia, G. A.; Bresser, D.; Reiter, J.; Oberhumer, P.; Sun, Y.-K.; Scrosati, B.; Passerini, S.; Hassoun, J. Interphase Evolution of a Lithium-Ion/Oxygen Battery. ACS Appl. Mater. Interfaces 2015, 7, 22638-22643.

(57) Liu, B.; Xu, W.; Tao, J.; Yan, P.; Zheng, J.; Engelhard Mark, H.; Lu, D.; Wang, C.; Zhang, J. G. Enhanced Cyclability of Lithium-Oxygen Batteries with Electrodes Protected by Surface Films Induced Via in Situ Electrochemical Process. Adv. Energy Mater. 2018, 8, 1702340-1702352.

(58) Oleg, S.; Vikram, P.; Abhishek, K.; Chayanit, C.; Venkatasubramanian, V. Quantifying the Promise of 'Beyond' Li-Ion Batteries. Transl. Mater. Res. 2015, 2, 045002-045023.

(59) Zhang, Y.-T.; Liu, Z.-J.; Wang, J.-W.; Wang, L.; Peng, Z.-Q. Recent Advances in Li Anode for Aprotic Li-O2 Batteries. Acta Phys-Chim. Sin. 2017, 33, 486-499.

(60) Yoshino, A. The Birth of the Lithium - Ion Battery. Angew. Chem. Int. Ed. 2012, 51, 5798-5800.

(61) Yao, X.; Dong, Q.; Cheng, Q.; Wang, D. Why Do Lithium-Oxygen Batteries Fail: Parasitic Chemical Reactions and Their Synergistic Effect. Angew. Chem. Int. Ed. 2016, 55, 11344-11353.

(62) Wu, S.; Qiao, Y.; Jiang, K.; He, Y.; Guo, S.; Zhou, H. Tailoring Sodium Anodes for Stable Sodium-Oxygen Batteries. Adv. Funct. Mater. 2018, 28, 1706374-1706382.

(63) Ren, X.; He, M.; Xiao, N.; McCulloch, W. D.; Wu, Y. Greatly Enhanced Anode Stability in K - Oxygen Batteries with an in Situ Formed Solvent - and Oxygen - Impermeable Protection Layer. Adv. Energy Mater. 2017, 7, 1601080-1601086.

(64) Franke-Lang, R.; Arlt, T.; Manke, I.; Kowal, J. X-Ray Tomography as a Powerful Method for Zinc-Air Battery Research. J. Power Sources 2017, 370, 45-51. 